\title{
Original
}

\section{Prevalence of Hypertension, Diabetes Mellitus, and Dyslipidemia in Patients with Chronic Obstructive Pulmonary Disease}

\author{
Mayumi S KATSURA ${ }^{1)}$, Takashi KATSURA ${ }^{2)}$, Tsukasa OHNISHI ${ }^{1)}$, \\ Takashi Hirose ${ }^{1)}$, Masaaki Matsukawa ${ }^{2)}$, Fumihide YoshidA $^{2)}$ \\ and Mitsuru ADACHI ${ }^{1)}$
}

\begin{abstract}
Recent studies have shown that chronic obstructive pulmonary disease (COPD) causes various extrapulmonary comorbidities. In addition, cardiovascular disease, the pathogenesis of which involves atherosclerosis, has been emphasized as a cause of mortality in patients with COPD. In the present study, we investigated the presence of classical risk factors for atherosclerosis in 183 patients with COPD. The prevalence of comorbidities (hypertension, diabetes mellitus $[\mathrm{DM}]$, and dyslipidemia) was investigated and compared with that in a general population. In patients with COPD, the prevalence of hypertension, DM, and dyslipidemia was $43.2 \%, 15.8 \%$, and $25.7 \%$, respectively, with the prevalence of DM and dyslipidemia significantly higher in patients than in the general population. Furthermore, there were significant differences in the prevalence of the three disorders in patients with COPD. For example, the prevalence of hypertension was significantly higher than that of diabetes mellitus in patients aged 60-69 years and higher than the prevalence of DM and dyslipidemia in patients aged $\geq 70$ years. Regardless of age, hypertension was noted in the greatest number of patients. In conclusion, a high proportion of patients with COPD were found to have the classical risk factors for atherosclerosis. In particular, the prevalence of DM and dyslipidemia was significantly higher in COPD patients than in the general population.
\end{abstract}

Key words : chronic obstructive pulmonary disease, comorbidity, prevalence, risk factors for atherosclerosis, general population

\section{Introduction}

Chronic obstructive pulmonary disease (COPD) is an inflammatory lung disease related to the long-term inhalation of noxious substances, including tobacco smoke. COPD is characterized by progressive airflow obstruction, which may not return to normal on respiratory function tests, exertional dyspnea, and chronic cough/sputum ${ }^{1)}$. In 2000, COPD was reported to be the fourth most common cause of mortality worldwide ${ }^{2)}$.

\footnotetext{
1) Division of Respiratory and Allergy, Department of Internal Medicine, Showa University School of Medicine, 1-5-8 Hatanodai, Shinagawa-ku, Tokyo 142-8666, Japan.

2) Department of Internal Medicine, Showa University Toyosu Hospital.
} 
Table 1. Characteristics of patients with COPD

\begin{tabular}{|c|c|c|}
\hline \multicolumn{2}{|c|}{ Number of patients } & 183 \\
\hline \multicolumn{2}{|c|}{ Male / Female, number } & $165 / 18$ \\
\hline \multicolumn{2}{|c|}{ Mean age (SD), years } & $74.2(8.1)$ \\
\hline \multicolumn{3}{|c|}{ Age-groups, number } \\
\hline \multicolumn{2}{|l|}{$50-59 y s$} & 6 \\
\hline \multicolumn{2}{|l|}{$60-69 y s$} & 51 \\
\hline \multicolumn{2}{|l|}{ 70ys- } & 126 \\
\hline \multicolumn{2}{|c|}{ Stage of COPD, number } & (Age-groups : number) \\
\hline I & 43 & $(50-59: 0,60-69: 11,70-: 32)$ \\
\hline II & 78 & $(50-59: 4,60-69: 24,70-: 50)$ \\
\hline III & 41 & $(50-59: 2,60-69: 13,70-: 26)$ \\
\hline IV & 21 & $(50-59: 0,60-69: 3,70-: 18)$ \\
\hline
\end{tabular}

Recent studies have shown that COPD causes various extrapulmonary comorbidities. Thus, it is important to recognize COPD not only as a respiratory disease, but also as a systemic disease ${ }^{3)}$. Cardiovascular disease, the pathogenesis of which involves atherosclerosis, has been reported to be responsible for approximately $30 \%$ of deaths in patients with $\mathrm{COPD}^{4,5)}$. Furthermore, hypertension, diabetes mellitus (DM), and dyslipidemia, classical risk factors for atherosclerosis, have been detected in a high proportion of COPD patients ${ }^{6-8)}$. However, few studies have reported on comorbidities of COPD in Japan. In the present study, we focused on hypertension, DM, and dyslipidemia as comorbidities of COPD and determined their prevalence in patients with COPD compared with that in a general population.

\section{Methods}

\section{Subjects}

The COPD group in the present retrospective study consisted of 183 patients who had periodically consulted the outpatient clinic of the Division of Respiratory and Allergy, Department of Internal Medicine, Showa University School of Medicine, or the Department of Internal Medicine, Showa University Toyosu Hospital for the treatment of COPD between April 2008 and March 2009 (165 males, 18 females; mean age 74.2 8.1 years [range 52-93 years]; Table 1). The general population used for comparisons was made up of people over 50 years of age who were selected based on data on hypertension, DM, and dyslipidemia from the National Health and Nutrition Survey (2006) published by the Ministry of Health, Labour and Welfare ${ }^{9)}$ (Table 2).

\section{Methodology}

Information was obtained regarding the patients' age, gender, stage of COPD, and the 
Table 2. Raw data of characteristics of the control group

(National Health and Nutrition Survey 2006)

\begin{tabular}{llccrr}
\hline Age-groups, y & & $50-59$ & $60-69$ & $70-$ & total \\
\hline Object of survey & & & & & \\
& & male / female & male / female & male / female \\
\hline Hypertension & object (n) & $363 / 544$ & $411 / 561$ & $504 / 631$ & 3014 \\
& prevalence (n) & $76 / 78$ & $130 / 170$ & $232 / 305$ & 991 \\
& prevalence (\%) & $20.9 / 14.3$ & $31.6 / 30.3$ & $46.0 / 48.3$ & 32.9 \\
\hline \multirow{2}{*}{ Dyslipidemia } & object (n) & $351 / 525$ & $390 / 527$ & $474 / 582$ & 2849 \\
& prevalence (n) & $31 / 68$ & $38 / 101$ & $49 / 140$ & 427 \\
& prevalence (\%) & $8.8 / 13.0$ & $9.7 / 19.2$ & $10.3 / 24.1$ & 15.0 \\
\hline \multirow{2}{*}{ Diabetes } & object (n) & $350 / 525$ & $389 / 523$ & $472 / 580$ & 2839 \\
& prevalence (n) & $17 / 12$ & $28 / 36$ & $56 / 49$ & 198 \\
& prevalence (\%) & $4.9 / 2.3$ & $7.2 / 6.9$ & $11.9 / 8.4$ & 7.0 \\
\hline
\end{tabular}

presence or absence of comorbidities (hypertension, DM, and dyslipidemia). The number of COPD patients with these comorbidities as a proportion of all patients was determined, as was the prevalence of the comorbidities with respect to age and stage of disease. The prevalence of hypertension, DM, and dyslipidemia was compared between the COPD patients and the general population. A diagnosis of COPD was made with stage assessment according to the Guidelines for the Diagnosis and Treatment of COPD (Chronic Obstructive Pulmonary Disease) issued by the Japanese Respiratory Society ${ }^{10)}$. Patients were determined to have hypertension, DM, or dyslipidemia if they were receiving drug therapy for that disease. Similarly, in the general population, any result reported as "person taking a drug" in the National Health and Nutrition Survey was taken as an indication that that person had the disease.

\section{Statistical analysis}

When comparing the prevalence of hypertension, DM, and dyslipidemia between COPD patients and the general population, data obtained from the National Health and Nutrition Survey for the "general population" in the present study were adjusted for age and gender in the COPD group using direct standardization methods. The Chi-squared test was used to compare percentages. $\mathrm{P}<0.05$ was considered significant.

\section{Results}

Significant differences were noted in the prevalence of three comorbidities in COPD patients : 79 patients (43.2\%) had hypertension, 47 (25.7\%) had dyslipidemia, and 29 (15.8\%) had DM (Table 3). Overall, 105 patients (57.4\%) were found to have at least one of the three comorbidities.

The prevalence of hypertension, DM, and dyslipidemia in patients aged 50-59 years was 
Table 3. Prevalence of comorbidities among patients with COPD $(\mathrm{n}=183)$

\begin{tabular}{lccl}
\hline Comorbidity & Number & $\%$ & \\
\hline Hypertension & 79 & 43.2 & $\bar{Z}$ \\
Dyslipidemia & 47 & 25.7 & $\bar{*}$ \\
Diabetes mellitus & 29 & 15.8 & $=*$ \\
\hline
\end{tabular}

* $: \mathrm{P}<0.05,{ }^{* *}: \mathrm{P}<0.001$

Table 4. Prevalence of comorbidities among patients with COPD according to each age group

\begin{tabular}{|c|c|c|c|}
\hline \multirow[t]{2}{*}{ Age-groups } & \multicolumn{3}{|c|}{ Comorbidity, \% (number) } \\
\hline & Hypertension & Dyslipidemia & Diabetes mellitus \\
\hline $50-59$ & $33.3(2)$ & $16.6(1)$ & 16.6（1） \\
\hline \multirow[t]{2}{*}{$60-69$} & $37.3(19)$ & $31.4(16)$ & $19.6(10)$ \\
\hline & \multicolumn{3}{|c|}{$*$} \\
\hline \multirow[t]{3}{*}{$70-$} & $46.0(58)$ & $23.8(30)$ & $14.3(18)$ \\
\hline & \multicolumn{2}{|c|}{$* *$} & \\
\hline & & $* *$ & \\
\hline
\end{tabular}

$*: \mathrm{p}<0.05, * *: \mathrm{P}<0.001$

Table 5. Prevalence of comorbidities among patients with COPD according to each COPD stage

\begin{tabular}{ccccc}
\hline COPD stage & \multicolumn{3}{c}{ Comorbidity, \% (number) } \\
\hline & & Hypertension & Dyslipidemia & Diabetes mellitus \\
\cline { 3 - 5 } I & $\mathrm{n}=43$ & $46.5(20)$ & $34.9(15)$ & $16.3(7)$ \\
II & $\mathrm{n}=78$ & $46.2(36)$ & $25.6(20)$ & $17.9(14)$ \\
III & $\mathrm{n}=41$ & $39.0(16)$ & $17.1(7)$ & $14.6(6)$ \\
IV & $\mathrm{n}=21$ & $33.3(7)$ & $23.8(5)$ & $9.5(2)$ \\
\hline
\end{tabular}

n.s. : not significant

$33.3 \%, 16.6 \%$, and $16.6 \%$, respectively; in the 60-69 years age group, the prevalence of the three comorbidities was $37.3 \%, 19.6 \%$, and $31.4 \%$, respectively; whereas in patients $\geq 70$ years of age, the prevalence was $46.0 \%, 14.3 \%$, and $23.8 \%$, respectively. There was a significant difference between the prevalence of hypertension and DM in subjects aged 60-69 years. Similarly, significant differences were found between the prevalence of hypertension and dyslipidemia / DM in patients aged $\geq 70$ years. The proportion of patients with hypertension was the highest, regardless of age (Table 4). There were no significant differences in the prevalence of these comorbidities in patients with different stages of the disease (Table 5).

To enable comparisons with COPD patients, a "general population" was created by age and gender adjustment of results from the National Health and Nutrition Survey. 
Table 6. Adjusted data of characteristics of the control group

\begin{tabular}{llccrr}
\hline Age-groups, $\mathrm{y}$ & & $50-59$ & $60-69$ & $70-$ & total \\
\hline Object of survey & & & & & \\
& & male / female & male / female & male / female & \\
\hline \multirow{2}{*}{ Hypertension } & object (n) & $38 / 97$ & $349 / 578$ & $891 / 1061$ & 3014 \\
& prevalence (n) & $8 / 14$ & $110 / 178$ & $409 / 523$ & 1242 \\
& prevalence (\%) & $21.0 / 14.4$ & $31.5 / 30.8$ & $45.9 / 49.3$ & 41.2 \\
\hline \multirow{2}{*}{ Dyslipidemia } & object (n) & $37 / 91$ & $331 / 545$ & $847 / 998$ & 2849 \\
& prevalence (n) & $4 / 6$ & $36 / 54$ & $97 / 124$ & 321 \\
& prevalence (\%) & $10.8 / 6.6$ & $10.9 / 9.9$ & $11.5 / 12.4$ & 11.3 \\
\hline \multirow{2}{*}{ Diabetes } & object (n) & $37 / 90$ & $330 / 543$ & $844 / 995$ & 2839 \\
& prevalence (n) & $2 / 3$ & $23 / 50$ & $98 / 111$ & 287 \\
& prevalence (\%) & $5.4 / 3.3$ & $7.0 / 9.2$ & $11.6 / 11.2$ & 10.1 \\
\hline
\end{tabular}

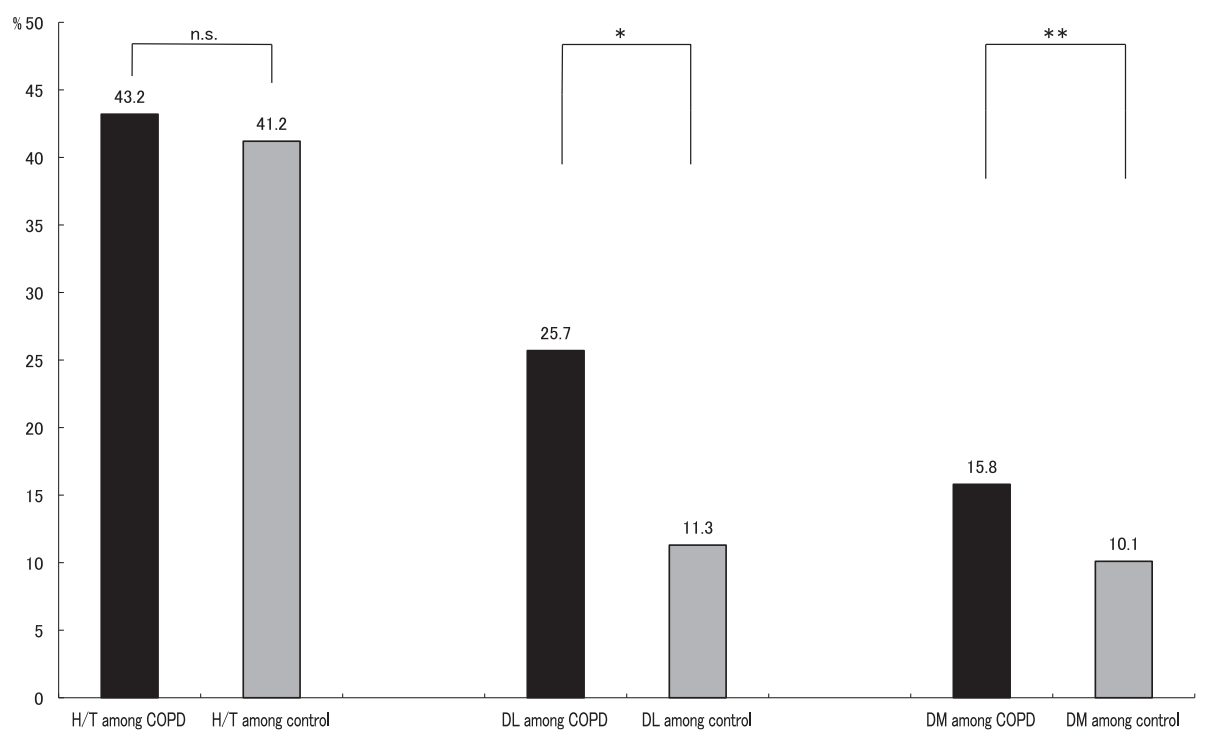

Fig. 1. Comparison of prevalence of comorbidities between COPD and control groups The prevalence of hypertension was not significantly different between COPD and control groups. The prevalence of dyslipidemia and diabetes mellitus in the COPD group was significantly higher than in the control group.

H / T: hypertension, DL : dyslipidemia, DM : diabetes mellitus, n.s. : not significant, ${ }^{*}: \mathrm{p}<0.001$, ${ }^{* *}: \mathrm{p}<0.05$

Following adjustment, 1242 of 3014 people (41.2\%) of the general population were found to have hypertension, 321 of $2849(11.3 \%)$ had dyslipidemia, and 287 of $2839(10.1 \%)$ had DM (Table 6). Comparison of the prevalence of these conditions between the general population and the COPD patients revealed that the prevalence of DM and dyslipidemia was significantly higher in patients with COPD. There was no significant difference in the prevalence of hypertension between the two groups (Fig. 1). 


\section{Discussion}

COPD has been reported to cause various extrapulmonary comorbidities and the importance of recognizing COPD as a systemic disease has been emphasized ${ }^{3)}$. As a comorbidity of COPD, cardiovascular disease in particular has been investigated as a cause of mortality in patients with COPD $^{4,11,12)}$.

Of the three comorbidities evaluated in the present study, namely hypertension, DM, and dyslipidemia, all of which are classical risk factors for atherosclerosis, hypertension was the most prevalent in patients with COPD, as reported previously ${ }^{6-8)}$. The second most frequent comorbidity was dyslipidemia, followed by DM. The prevalence of DM and dyslipidemia was significantly higher in COPD patients than in the general population. The prevalence of hypertension increased with age, showing significant differences compared with the other comorbidities. However, there was no significant difference in the prevalence of hypertension between COPD patients and the general population, suggesting the influence of age.

Recent studies have revealed the presence of systemic inflammation in patients with COPD ${ }^{13-15)}$. Because various chronic comorbidities related to systemic inflammation have been observed, "chronic systemic inflammatory syndrome" has been introduced as a disease entity ${ }^{16)}$. Therefore, in the present study, it may be that COPD-specific systemic inflammation contributed to a significant increase in impaired glucose/lipid metabolism in patients with COPD. However, this requires further investigation, with the precise etiology and mechanisms underlying the dyslipidemia and DM in COPD patients yet to be determined.

The pathogenesis of cardiovascular disease in the presence of COPD is unclear. A recent study reported that inflammation was involved in the onset and deterioration of atherosclerosis, and so atherosclerosis has been recognized as an inflammatory disease ${ }^{17)}$, as has COPD. In addition, many studies have suggested that systemic inflammation in COPD patients contributes to the development of cardiovascular disease ${ }^{18-25)}$. Taking these findings into consideration, the development of cardiovascular disease in the presence of COPD may be due to an additive/synergistic effect of systemic inflammation and classical risk factors for atherosclerosis.

In the present study, approximately $60 \%$ of COPD patients had classical risk factors for atherosclerosis. In particular, the prevalence of DM and dyslipidemia was significantly higher in COPD patients than in the general population. Thus, controlling atherosclerosis in COPD patients may prevent the development of cardiovascular disease, subsequently improving the prognosis for these patients. Therefore, in the clinical management of COPD, screening for and the treatment of any classical risk factors for atherosclerosis may prove to be important, recognizing COPD as a systemic disorder.

\section{Acknowledgment}

This study was sponsored by the Showa University Medical Foundation. 


\section{References}

1) Definition. In: Guidelines for the Diagnosis and Treatment of COPD (Chronic Obstructive Pulmonary Disease), 3rd ed. Committee for the Third Edition of the COPD Guidelines of The Japanese Respiratory Society (Ed), The Japanese Respiratory Society, Tokyo, pp 2-5 (2009) (in Japanese)

2) Lopez AD, Shibuya K, Rao C, Mathers CD, Hansell AL, Held LS, Schmid V and Buist S: Chronic obstructive pulmonary disease: current burden and future projections. Eur Respir J $27:$ 397-412 (2006)

3) Barnes PJ and Celli BR: Systemic manifestations and comorbidities of COPD. Eur Respir J 33 : 1165-1185 (2009)

4) Calverley PM, Anderson JA, Celli B, Ferguson GT, Jenkins C, Jones PW, Yates JC and Vestbo J : Salmeterol and fluticasone propionate and survival in chronic obstructive pulmonary disease. N Engl J Med 356:775-789 (2007)

5) Mannino DM, Dohertya DE and Sonia Buist A : Global initiative on Obstructive Lung Disease (GOLD) classification of lung disease and mortality: finding from the Atherosclerosis Risk in Communities (ARIC) study. Respir Med $100:$ 115-122 (2006)

6) Terzano C, Conti V, Di Stefano F, Petroianni A, Ceccarelli D, Graziani E, Mariotta S, Ricci A, Vitarelli A, Puglisi G, De Vito C, Villari P and Allegra L: Comorbidity, hospitalization, and mortality in COPD : results from a longitudinal study. Lung 188 : 321-329 (2010)

7) Barr RG, Celli BR, Mannino DM, Petty T, Rennard SI, Sciurba FC, Stoller JK, Thomashow BM and Turino GM : Comorbidities, patient knowledge, and disease management in a national sample of patients with COPD. Am J Med 122 : 348-355 (2009)

8) Cilli A, Uslu A, Ogus C and Ozdemir T: KOAH'da komorbiditenin prognoza etkisi. Tuberc Toraks 52 : 52-55 (2004)

9) Office for Life-style Related Diseases Control Health Service Bureau Ministry of Health, Labour and Welfare: Summary results of the national health and nutrition survey Japan, 2006. Health Welfare Stat 55(10): 42-50 (2008) (in Japanese)

10) Diagnosis. In: Guidelines for the Diagnosis and Treatment of COPD (Chronic Obstructive Pulmonary Disease), 3rd ed. Committee for the Third Edition of the COPD Guidelines of The Japanese Respiratory Society (Ed), The Japanese Respiratory Society, Tokyo, pp 32-67 (2009) (in Japanese)

11) Holguin F, Folch E, Redd SC and Mammini DM : Comorbidity and mortality in COPD-related hospitalizations in the United States, 1979 to 2001. Chest 128:2005-2011 (2005)

12) Celli BR, Cote CG, Martin JM, Casanova C, Montes de Oca M, Mendez RA, Pinto Plata V and Cabral HJ : The body-mass index, airflow obstruction, dyspnea, and exercise capacity index in chronic obstructive pulmonary disease. N Engl J Med 350 : 1005-1012 (2004)

13) Man SF, Connett JE, Anthonisen NR, Wise RA, Tashkin DP and Sin DD : C-reactive protein and mortality in mild to moderate chronic obstructive pulmonary disease. Thorax 61:849-853 (2006)

14) Schols AM, Buurman WA, Staal van den Brekel AJ, Dentener MA and Wouters EF : Evidence for a relation between metabolic derangements and increased levels of inflammatory mediators in a subgroup of patients with chronic obstructive pulmonary disease. Thorax 51:819-824 (1996)

15) Gan WQ, Man SF, Senthilselvan A and Sin DD: Association between chronic obstructive pulmonary disease and systemic inflammation: a systematic review and a meta-analysis. Thorax 59: 574-580 (2004)

16) Fabbri LM and Rabe KF : From COPD to chronic systemic inflammatory syndrome? Lancet 370: 797-799 (2007)

17) Ross R : Atherosclerosis - an inflammatory disease. N Engl J Med 340 : 115-126 (1999)

18) Sevenoaks MJ and Stockley RA : Chronic obstructive pulmonary disease, inflammation and co-morbidity - a common inflammatory phenotype? Respir Res 7: 70 (2006)

19) Han MK, McLaughlin VV, Criner GJ and Martinez FJ : Pulmonary diseases and the heart. Circulation 116 : 2992-3005 (2007) 
20) Maclay JD, McAllister DA and Macnee W: Cardiovascular risk in chronic obstructive pulmonary disease. Respirology $12: 634-641$ (2007)

21) Anderson D and Macnee W: Targeted treatment in COPD : a multi-system approach for a multi-system disease. Int J Chron Obstruct Pulmon Dis 4 : 321-335 (2009)

22) Stockley RA, O’Brien C, Pye A and Hill SL: Relationship of sputum color to nature and outpatient management of acute exacerbations of COPD. Chest $117: 1638-1645$ (2000)

23) Wedzicha JA, Seemungal TA, MacCallum PK, Paul EA, Donaldson GC, Bhowmik A, Jeffries DJ and Meade TW: Acute exacerbations of chronic obstructive pulmonary disease are accompanied by elevations of plasma fibrinogen and serum IL-6 levels. Thromb Haemost $84:$ 210-215 (2000)

24) Almagro P, Calbo E, Ochoa de Echagüen A, Barreiro B, Quintana S, Heredia JL and Garau J : Mortality after hospitalization for COPD. Chest $121: 1441-1448$ (2002)

25) Sin DD and Man SF: Why are patients with chronic obstructive pulmonary disease at increased risk of cardiovascular diseases? The potential role of systemic inflammation in chronic obstructive pulmonary disease. Circulation 107 : 1514-1519 (2003)

[Received July 13, 2010 : Accepted March 8, 2011] 